\title{
Number of motile spermatozoa inseminated and pregnancy outcomes in intrauterine insemination
}

\author{
Palma G. Gubert, Jessica Pudwell, Dean Van Vugt, Robert L. Reid and Maria P. Velez* (D)
}

\begin{abstract}
Purpose: To determine whether age modifies the effect of the number of motile spermatozoa inseminated (NMSI) as a predictor of success in Intrauterine Insemination (IUI).

Methods: This retrospective cohort study included all patients who underwent IUI at an academic infertility center between October 2004 and June 2018. The primary outcome was clinical pregnancy (CP; a gestational sac and fetal heartbeat on ultrasound). Results were analyzed by patient factors including age, NMSI, duration of infertility, and cause of infertility, along with treatment factors such as number of follicles and ovulation induction protocol. Factors associated with the odds of achieving a clinical pregnancy were analyzed using binary logistic generalized estimating equations to control for clustering effects by couple. Female age was categorized as $<35$ years vs. $\geq 35$ years.

Results: Seven hundred thirty-seven couples that underwent 2062 IUI cycles for heterogeneous indications were included. The overall CP rate was $15.1 \%$ per cycle, and the cumulative CP rate per couple was $35.9 \%$. For females $<35$ years, the odds of CP per cycle were reduced for NMSI categories $\left(\times 10^{6}\right)$ of $<5.0$ vs. $\geq 10.0(\mathrm{OR}=0.49 ; 95 \% \mathrm{Cl} 0.29-$ 0.83); the odds of CP per cycle did not differ for NMSI 5.0-9.9 vs. $\geq 10.0$ (OR=0.66; 0.37-1.18). For those $\geq 35$ years, no difference was seen in the odds of CP per cycle for NMSI categories $<5.0$ vs. $\geq 10.0$ (OR $=1.55$; 95\% Cl 0.72-3.31) or 5.0-9.9 vs. $\geq 10.0(\mathrm{OR}=1.04 ; 95 \% \mathrm{Cl} 0.48-2.27)$.

Conclusions: These results suggest that the NMSI can be used as a predictor of success in IUI in couples with women who are $<35$ years of age; these patients should be counselled about their lower pregnancy rates when the NMSI is $<5.0 \times 10^{6}$. In patients $\geq 35$ years, the NMSI does not appear to be a useful predictor of success. Further studies with larger sample size should be conducted.
\end{abstract}

Keywords: Assisted reproduction, Intrauterine insemination, Pregnancy rates

\section{Background}

Intrauterine insemination (IUI) is a cost-effective strategy and first line approach for the treatment of couples with unexplained and mild male infertility [1-3]. It involves the insertion of a high number of washed spermatozoa directly into the uterus at the time of ovulation to increase the chance of a pregnancy. IUI is often combined with ovarian stimulation (OS) to increase the number of eggs ovulating in a given cycle. Certain patient-related factors may indicate a poor chance of success with IUI, such as tubal disease or

\footnotetext{
* Correspondence: maria.velez@queensu.ca

Department of Obstetrics and Gynaecology, Division of Reproductive

Endocrinology and Infertility, Queen's University, Kingston Health Sciences Centre, 76 Stuart Street, Victory 4, Kingston, ON K7L 2V7, Canada
}

severe male factor infertility; such couples should be advised to proceed directly to other assisted reproductive technologies (ARTs), such as in vitro fertilization (IVF) and intracytoplasmic sperm injection (ICSI) when indicated.

Many factors have been considered for their potential role as both predictors and optimizers of the success of IUI, including type and duration of infertility, number of mature follicles, endometrial thickness, and various seminal parameters [4]. The sperm parameters most frequently examined in relation to pregnancy rates are (i) number of motile spermatozoa inseminated (NMSI); (ii) sperm morphology using strict criteria; (iii) total motile sperm count (TMSC) in the native sperm sample; and (iv) total motility in the native sperm sample [5]. Current evidence does not allow to define

(c) The Author(s). 2019 Open Access This article is distributed under the terms of the Creative Commons Attribution 4.0 International License (http://creativecommons.org/licenses/by/4.0/), which permits unrestricted use, distribution, and reproduction in any medium, provided you give appropriate credit to the original author(s) and the source, provide a link to the Creative Commons license, and indicate if changes were made. The Creative Commons Public Domain Dedication waiver (http://creativecommons.org/publicdomain/zero/1.0/) applies to the data made available in this article, unless otherwise stated. 
clear lower cut-off levels of pre- or postwash sperm parameters below which IUI should not be performed [1]. A recent systematic review concluded that a TMSC $>1$ million and a morphology $>4 \%$ are of possible prognostic value, in such a case that below these cut-off levels IUI should be withheld, however the quality of evidence was low [5]. In 2004, a meta-analysis of 16 studies assessing NMSI and IUI outcomes, concluded that at cut-off levels between 0.8 and 5 million, the specificity of the NMSI, defined as the ability to predict failure to become pregnant, was as high as $100 \%$; and the sensitivity of the test, defined as the ability to predict pregnancy, was limited [6]. Subsequent studies have been conducted $[7,8]$, however there is not yet a consensus on a minimum recommended NMSI threshold, below which, IUI is unlikely to result in a pregnancy.

Such NMSI thresholds are typically reported for female patients of all ages pursuing IUI, up to a maximum age [5, 7-10]. Female age is known to be an independent predictor of IUI success [11] but the effect of NMSI on pregnancy rates according to female age has been less studied $[12,13]$. The purpose of this study was thus to determine whether age modifies the effect of NMSI as a predictor of success in IUI.

\section{Methods}

This was a retrospective cohort study comprising patients that underwent IUI at the Fertility Clinic at the Kingston General Hospital in Kingston, Ontario, Canada between October 2004 and June 2018.

Before entry into the IUI program, patients were investigated to determine the cause of infertility, with investigations conducted as necessary to elicit etiology. Female patients had tubal patency confirmed by hysterosalpingogram, and men had a semen analysis. Causes of infertility were grouped into male factor, female factor (ovulatory dysfunction, mild to moderate endometriosis, and diminished ovarian reserve), combined male and female factors, and unexplained infertility.

The primary outcome was clinical pregnancy $(\mathrm{CP})$, defined by a gestational sac and fetal heartbeat on ultrasound. The secondary outcomes were $\beta$-HCG positive pregnancy and live birth. Additional information collected from the chart review included duration of infertility, number of mature follicles, ovulation induction protocol, and live birth outcomes. Female age was categorized as $<35$ years vs. $\geq 35$ years. Charts were excluded if the primary outcome $(\mathrm{CP})$ or the primary exposure (NMSI) were missing.

\section{Ovulation induction protocol and monitoring}

Most patients underwent OS ovarian stimulation with gonadotropins, while a minor proportion received clomiphene or letrozole, or a combination of clomiphene or letrozole and gonadotropins. Some women chose to undergo monitoring alone without ovarian stimulation, or self-monitoring at home with an LH-detection kit. The protocol for each patient was determined by their weight, previous medical history, and reason for infertility. Ovarian response was monitored by ultrasound follicle tracking combined with hormonal assessment (estradiol and/or luteinizing hormone). The cycle was cancelled if there was evidence of ovarian hyperstimulation. When at least one dominant follicle measured greater than $17 \mathrm{~mm}$, ovulation was induced with hCG or recombinant $\mathrm{LH}$.

\section{Sperm wash protocol}

Semen was collected by masturbation into a sterile plastic specimen container either at home or in the clinic. Samples were processed within $15 \mathrm{~min}$ of arrival (no more than $60 \mathrm{~min}$ from the time of ejaculation). Semen was transferred into a $15 \mathrm{ml}$ sterile tube containing a gradient consisting of $2 \mathrm{ml} 45 \%$ and $2 \mathrm{ml} 80 \%$ salinized silica (Gynotech; Malden, Netherlands) and centrifuged for $30 \mathrm{~min}$ at $400 \mathrm{~g}$. The seminal plasma and gradient were aspirated and the remaining pellet was resuspended in $2 \mathrm{ml}$ Sperm Wash Medium (Gynotech). Following a 6-min centrifugation at $300 \mathrm{~g}$, the supernatant was removed, and the pellet was resuspended in $0.4 \mathrm{ml}$ of Sperm Wash Medium.

\section{Insemination procedure}

One insemination was performed approximately $36 \mathrm{~h}$ after administration of the ovulation triggering medication, employing a single use intra-uterine insemination cannula with shape memory (Laboratoire CCD, product code $12040 \mathrm{MF}$ ), to allow angulation as required for intrauterine insemination. Women were instructed to take the ovulation triggering medication at 10:00 pm, and the IUI was performed $36 \mathrm{~h}$ after, around 10:00 a.m).

\section{Statistical analysis}

Results were analyzed both by cycle and by couple (for a cumulative pregnancy rate). This cumulative pregnancy rate was calculated by grouping a patient's cycles into a "round" of cycles; a round was finished when a $\beta$-HCG positive pregnancy was achieved, or treatment was stopped. A similar method is described by Lemmens, et al., 2016 [14].

In analyses completed per round, the mean NMSI over all cycles in a round was calculated and used to represent the overall NSMI in the round. To confirm that this was an appropriate representation, two Spearman Correlations were calculated. First, between mean NMSI per round and NMSI for each cycle, and second, between mean NSMI per round and the NMSI for the last cycle 
in the round. For each, a 95\% confidence interval was calculated.

Results were summarized using descriptive statistics, as a count and percent of total, mean and standard deviation, or median and interquartile range. Results were summarized using the median and interquartile if the data was ordinal or not normally distributed as determined by the Shapiro-Wilk test. Clinical pregnancy rates and associated $95 \%$ confidence intervals were calculated. The Chi-Square test was used to compare the number of pregnancies achieved between the different OS protocols. The Chi-Square test for trend was used to compare the number of pregnancies achieved as female age, NMSI and number of mature follicles increased. Factors associated with the odds of achieving a clinical pregnancy were analyzed using binary logistic generalized estimating equations to control for clustering effects by couple. Patient factors including age, NMSI, duration of infertility, and cause of infertility were included, along with treatment factors such as number of follicles and ovulation induction protocol. $P<0.05$ was considered statistically significant. Statistical analysis was completed with IBM SPSS Statistics v24.

\section{Results}

A total of 737 couples and 2062 cycles were included in this study. The median female age at entry to care was

Table 1 Baseline characteristics of the population by couple at entry to care

\begin{tabular}{ll}
\hline & $\begin{array}{l}\text { Total Couples } \\
(N=737)\end{array}$ \\
\hline Female Age (years), median [IQR] & $33(30-36.5)$ \\
Range & $25-42$ \\
Female Age categories, $\mathrm{n}(\%)$ & \\
$<30$ & $151(20.5)$ \\
$30-34$ & $305(41.4)$ \\
$35-39$ & $234(31.8)$ \\
$\geq 40$ & $46(6.3)$ \\
Cause of Infertility, $\mathrm{n}(\%)$ & \\
Male factor & $138(18.7)$ \\
Female factor & $244(33.1)$ \\
Male \& female factor & $49(6.6)$ \\
Unexplained & $274(37.2)$ \\
Not recorded & $32(4.3)$ \\
Duration of infertility (months), $\mathrm{n}(\%)$ & \\
$<12$ & $64(10.1)$ \\
12-23 & $285(45.2)$ \\
$24-35$ & $156(24.7)$ \\
$\geq 36$ & $126(20.0)$ \\
Unknown, $\mathrm{n}$ & 106 \\
\hline
\end{tabular}

33.0 years [IQR 30-36.5]. Unexplained and female factor were the most common causes of infertility, and most patients had experienced infertility for greater than 1 year (Table 1).

Characteristics of care are summarized in Table 2. The median number of total cycles per couple was 3 [IQR 24]. $85.6 \%$ of couples completed only one round of care; $11.8 \%$ completed two, and $2.6 \%$ completed $\geq 3$ rounds. A total of 869 rounds of care were included, comprised of a median number of 2 cycles [IQR 1-3] per round. Among the 2062 cycles, the median NMSI per cycle was

Table 2 Characteristics of care

Total Couples $N=737$

Total Number of Rounds of Care Per Couple, n (\%)

1

$631(85.6)$

2

$87(11.8)$

$3+$

$19(2.6)$

Total Cycles per Couple, median [IQR] $3(2-4)$

Range

$1-22$

Total Cycles per Couple, n (\%)

1

$178(24.2)$

$161(21.8)$

$193(26.2)$

$101(13.7)$

98 (13.3)

5-9

$6(0.8)$

Total Rounds of Care

$N=869$

Number of Cycles per Round of Care, median [IQR]

$2[1-3]$ Range

$1-14$

Total Number of Cycles per Round of Care, $n$ (\%)

1

$312(35.9)$

2

3

$210(24.2)$

$190(21.9)$

$90(10.4)$

$53(6.1)$

5-6

$17(1.5)$

7-14

Total Cycles

$N=2062$

NMSI per Cycle

Median [IQR]

$22.4[7.8-53.2]$

Unknown

3

Follicles per Cycle

Median [IQR]

2 [1-3]

Unknown 
Table 3 Pregnancy outcomes by cycles and rounds

\begin{tabular}{|c|c|c|c|}
\hline $\begin{array}{l}\text { Total Cycles } \\
N=2062\end{array}$ & $\begin{array}{l}\text { Total } \\
\text { N (\%) }\end{array}$ & $\begin{array}{l}\text { Clinical Pregnancy } \\
\text { N [Rate }(95 \% \text { Cl)] }\end{array}$ & $P$-Value \\
\hline \multicolumn{4}{|l|}{ Overall } \\
\hline & $2062(100.0)$ & $312[15.1(13.6-16.7)]^{\mathrm{b}}$ & \\
\hline \multicolumn{4}{|l|}{ NMSI $\left(\times 10^{6}\right)$} \\
\hline$<1$ & $80(3.9)$ & $3[3.8(1.1-9.7)]$ & \multirow[t]{5}{*}{$0.0007^{\delta}$} \\
\hline $1-4$ & $283(13.7)$ & $36[12.7(9.2-17.0)]$ & \\
\hline $5-9$ & $245(11.9)$ & $30[12.2(8.6-16.8)]$ & \\
\hline$\geq 10$ & $1454(70.5)$ & $243[16.7(14.9-18.7)]^{\mathrm{b}}$ & \\
\hline Unknown & 3 & & \\
\hline \multicolumn{4}{|l|}{ Age (Years) } \\
\hline$<30$ & $348(16.9)$ & $59[17.0(13.3-21.2)]$ & \multirow[t]{4}{*}{$0.09^{\delta}$} \\
\hline $30-34$ & $862(41.8)$ & $135[15.7(13.4-18.2)]$ & \\
\hline $35-39$ & $723(35.1)$ & $104[14.4(12.0-17.1)]$ & \\
\hline$\geq 40$ & $129(6.3)$ & $14[10.9(6.4-17.1)]$ & \\
\hline \multicolumn{4}{|l|}{ OS Protocol } \\
\hline None & $124(6.1)$ & $6[4.8(2.0-9.7)]$ & \multirow[t]{4}{*}{$0.0003^{\beta}$} \\
\hline Letrozole or Clomid & $210(10.4)$ & $22[10.5(6.9-15.2)]^{a}$ & \\
\hline Gonadotropins ( \pm Letrozole or Clomid) & $1690(83.5)$ & $280[16.6(14.9-18.4)]^{\mathrm{a}}$ & \\
\hline Unknown & 38 & & \\
\hline \multicolumn{4}{|l|}{ Number of Mature Follicles } \\
\hline 1 & $805(41.9)$ & $101[12.6(10.4-15.0)]^{a}$ & \multirow[t]{7}{*}{$<0.0001^{\delta}$} \\
\hline 2 & $565(29.4)$ & $86[15.2(12.4-18.4)]$ & \\
\hline 3 & $284(14.8)$ & $59[20.8(16.4-25.9)]^{a}$ & \\
\hline 4 & $126(6.6)$ & $28[22.2(15.6-30.1)]$ & \\
\hline$\geq 5$ & $141(7.3)$ & $29[20.6(14.5-27.8)]$ & \\
\hline Unknown & 141 & & \\
\hline $\begin{array}{l}\text { Total Rounds } \\
N=869\end{array}$ & $\begin{array}{l}\text { Total } \\
\text { N (\%) }\end{array}$ & $\begin{array}{l}\text { Clinical Pregnancy } \\
\text { N [Rate }(95 \% \mathrm{Cl})]\end{array}$ & \\
\hline \multicolumn{4}{|l|}{ Overall } \\
\hline & $869(100.0)$ & $312[35.9(32.8-39.1)]$ & \\
\hline \multicolumn{4}{|l|}{ Average NMSI $\left(\times 10^{6}\right)$} \\
\hline$<1$ & $45(5.3)$ & $4[8.9(3.1-19.8)]$ & \multirow[t]{5}{*}{$<0.0001^{\delta}$} \\
\hline $1-4$ & $93(10.9)$ & $26[28.0(19.6-37.6)]$ & \\
\hline $5-9$ & $74(8.7)$ & $26[35.1(25.0-46.4)]$ & \\
\hline$\geq 10$ & $643(75.2)$ & $249[38.7(35.0-42.5)]$ & \\
\hline Unknown & 14 & & \\
\hline \multicolumn{4}{|l|}{ Age at Start of Round (Years) } \\
\hline$<30$ & $162(18.6)$ & $65[40.1(32.8-47.8)]$ & \multirow[t]{4}{*}{$0.03^{\delta}$} \\
\hline $30-34$ & $364(41.9)$ & $136[37.4(32.5-42.4)]$ & \\
\hline $35-39$ & $287(33.0)$ & 98 [34.1 (28.8-39.8)] & \\
\hline$\geq 40$ & $56(6.4)$ & $13[23.2(13.7-35.4)]$ & \\
\hline
\end{tabular}

${ }^{a} 1$ unknown clinical pregnancy outcome

${ }^{b} 2$ unknown clinical pregnancy outcomes

${ }^{\delta} X^{2}$ test for trend

${ }^{\beta} X^{2}$ test 
22.4 $\left(\times 10^{6}\right)$ [IQR 7.8-53.2] and the median number of follicles per cycle was 2 [IQR 1-3].

In analyses by round, the average NMSI over all cycles was used. In order to examine the validity of using this summary measure we calculated the Spearman Correlation between mean NMSI per round and NMSI for all cycles $(0.89$; 95\% CI 0.88-0.90). The Spearman Correlation between mean NMSI per round and NMSI for the last cycle in the round $(0.93 ; 95 \%$ CI $0.92-0.94)$.

Pregnancy outcomes by cycles and by rounds are presented in Table 3. A total of 312 CPs resulted from 2062 cycles for an overall $\mathrm{CP}$ rate per cycle of $15.1 \%$ (95\% CI 13.6-16.7). CP rates per cycle according to NMSI category, female age category, OS protocol, and number of mature follicles are also presented. The CP rate per round was $35.9 \%$ (95\% CI 32.8-39.1). When divided into NMSI categories $\left(\times 10^{6}\right)$ of $<1,1-4,5-9$, and $\geq 10$, the resulting CP rates were $8.9,28.0,35.1$, and $38.7 \%$ per round, respectively ( $\mathrm{P}$ Trend $<0.001$ ). When divided into age categories of $<30,30-34,35-39$, and $\geq$ 40 years, the resulting $\mathrm{CP}$ rates were $40.1,37.4,34.1$, and $23.2 \%$ per round, respectively ( $\mathrm{P}$ Trend $=0.03$ ).

The impact of patient factors on the odds of clinical pregnancy per round of care are presented in Table 4. Increasing female age $(\mathrm{OR}=0.96 ; 95 \% \mathrm{CI}$ 0.92-0.99), average NMSI $<1.0\left(\times 10^{6}\right)(\mathrm{OR}=0.21 ; 95 \% \mathrm{CI} 0.07$, $0.62)$ and duration of infertility $\geq 36$ months ( $O R=0.50$, 95\% CI 0.27-0.94) were associated with decreased odds of clinical pregnancy.

Table 4 Patient factors and odds of clinical pregnancy per round of care

\begin{tabular}{llll}
\hline $\begin{array}{l}N=733 \\
\text { Female Age }\end{array} \quad$ OR & $95 \% \mathrm{Cl}$ & $P$-Value \\
$\quad \begin{array}{l}\text { Years } \\
\text { Average NMSI }\end{array}$ & 0.96 & $0.92-0.997$ & $<0.05$ \\
$\quad<1$ & 0.21 & $0.07-0.62$ & $<0.01$ \\
$1-4$ & 0.71 & $0.41-1.24$ & 0.23 \\
$5-9$ & 1.00 & $0.57-1.73$ & 0.99 \\
$\geq 10$ & Ref & - & - \\
Duration of Infertility & & & \\
$\quad<12$ & Ref & - & - \\
$12-23$ & 0.81 & $0.47-1.40$ & 0.44 \\
$24-35$ & 0.85 & $0.47-1.53$ & 0.58 \\
$\quad \geq 36$ & 0.50 & $0.27,0.94$ & $<0.05$ \\
Cause of Infertility & & & 0.34 \\
Unexplained & 1.19 & $0.84-1.69$ & 0.12 \\
Male \& Female Factor & 0.54 & $0.25-1.17$ & 0.33 \\
Male Factor & 0.78 & $0.47-1.29$ & - \\
Female Factor & Ref & - & \\
\hline
\end{tabular}

Table 5 presents two models of the impact of patient factors (Model 1) and patient and treatment factors (Model 2) on the odds of CP per cycle. In Model 1, CP odds were significantly decreased when NMSI was $<1 \times$ $10^{6}(\mathrm{OR}=0.18 ; 95 \%$ CI 0.04-0.77) and when the etiology of infertility was male factor $(\mathrm{OR}=0.64$; $95 \%$ CI 0.41 0.99). In Model 2, CP odds were significantly decreased with NMSI $<1 \times 10^{6} \quad(\mathrm{OR}=0.20 ; 95 \%$ CI $0.05-0.91)$, male factor infertility ( $\mathrm{OR}=0.52$; $95 \%$ CI $0.33-0.83)$, use of one mature follicle (OR $=0.59 ; 95 \%$ CI $0.39-0.89$ ), and use of clomiphene or letrozole vs. gonadotropin or no OS treatment $(\mathrm{OR}=0.51 ; 95 \%$ CI $0.31-0.85)$.

Models assessing the odds of CP per cycle according to female age category ( $<35$ vs. $\geq 35$ years) are in Table 6 . Due to small cell counts the $<1$ and 1-4 NMSI categories were combined for these models. For females $<35$ years, the odds of CP per cycle were reduced for NMSI $<5.0$ vs. $\geq 10.0$ ( $\mathrm{OR}=0.49$; $95 \%$ CI $0.29-0.83$ ); the odds of CP per cycle did not differ for NMSI 5.0-9.9 vs. $\geq 10.0$. For those $\geq 35$ years, no difference was seen for NMSI $<5.0$ or $5.0-9.9$ compared to $\geq 10.0$. The adjusted model is similar (Fig. 1).

Among the 312 recorded clinical pregnancies, outcomes on 262 pregnancies were available (Table 7). The outcomes of 50 CPs were unknown, as antenatal and delivery care was not completed at our center. Among those 262 pregnancies, there were 220 live births, 36 losses, and 6 who were still pregnant at the time of chart review. Detailed chart reviews were conducted on the 196 participants who delivered at our center. Among these patients, $79.1 \%$ delivered at term, $59.7 \%$ delivered vaginally, and $82.7 \%$ had a singleton delivery. In terms of pregnancy complications, $10.7 \%$ experienced a hypertensive disorder and $8.7 \%$ had gestational diabetes. Among the term babies, the average birthweight was $3404 \pm 542$ $\mathrm{g}$ and $97.1 \%$ had a normal APGAR score $(\geq 7)$ at $5 \mathrm{~min}$.

\section{Discussion}

In this study, 312 CPs were achieved from 2062 IUI cycles, resulting in a $15.1 \% \mathrm{CP}$ rate per cycle and $35.9 \%$ per round. These pregnancy rates are comparable to those of other reports [7, 9, 10, 12]. During statistical analysis in studies such as this, it is important to consider that multiple cycles in the same patient are not independent of one another, and this may influence results. This is not taken into consideration in per cycle results, but for this reason, we also analyzed the data according to rounds of care. Other strengths of this study include the large cohort of patients, the heterogeneous indications, and wide age range of patients (including 129 cycles in patients over 40 years of age).

There is discrepancy in the primary outcomes used in many studies on IUI outcomes, as some use serum-positive pregnancy rate [7], and others use the presence of a 
Table 5 Impact of patient factors (Model 1) and patient and treatment factors (Model 2) on the odds of Clinical pregnancy per cycle

\begin{tabular}{|c|c|c|c|c|c|c|}
\hline & \multicolumn{3}{|c|}{$\begin{array}{l}\text { Model } 1 \\
N=1795 \text { Cycles from } 626 \text { Couples }\end{array}$} & \multicolumn{3}{|c|}{$\begin{array}{l}\text { Model } 2 \\
N=1667 \text { from } 588 \text { Couples }\end{array}$} \\
\hline & $\overline{O R}$ & $95 \% \mathrm{Cl}$ & P-Value & $\overline{O R}$ & $95 \% \mathrm{Cl}$ & $P$-Value \\
\hline \multicolumn{7}{|l|}{ Female Age (Years) } \\
\hline & 0.97 & $0.94-1.01$ & 0.11 & 0.97 & $0.93-1.00$ & 0.056 \\
\hline \multicolumn{7}{|l|}{ NMSI } \\
\hline$<1$ & 0.18 & $0.04-0.77$ & 0.021 & 0.20 & $0.05-0.91$ & 0.036 \\
\hline $1-4$ & 0.87 & $0.55-1.40$ & 0.57 & 0.81 & $0.49-1.34$ & 0.42 \\
\hline $5-9$ & 0.77 & $0.48-1.24$ & 0.29 & 0.77 & $0.47-1.27$ & 0.31 \\
\hline$\geq 10$ & Ref & - & - & Ref & - & - \\
\hline \multicolumn{7}{|c|}{ Duration of Infertility (Months) } \\
\hline$<12$ & Ref & - & - & Ref & - & - \\
\hline $12-23$ & 0.86 & $0.52-1.42$ & 0.56 & 0.98 & $0.59-1.65$ & 0.95 \\
\hline $24-35$ & 0.99 & $0.58-1.67$ & 0.96 & 0.99 & $0.57-1.70$ & 0.97 \\
\hline$\geq 36$ & 0.60 & $0.34,1.07$ & 0.081 & 0.61 & $0.34-1.12$ & 0.11 \\
\hline \multicolumn{7}{|l|}{ Cause of Infertility } \\
\hline Unexplained & 0.95 & $0.69-1.32$ & 0.760 .87 & 0.87 & $0.62-1.23$ & 0.43 \\
\hline Male \& Female Factor & 0.52 & $0.19-1.46$ & 0.21 & 0.58 & $0.21-1.59$ & 0.29 \\
\hline Male Factor & 0.64 & $0.41-0.99$ & 0.045 & 0.52 & $0.33-0.83$ & 0.006 \\
\hline Female Factor & Ref & - & - & Ref & - & - \\
\hline \multicolumn{7}{|l|}{ Number of Follicles } \\
\hline 1 & & & & 0.59 & $0.39-0.89$ & 0.011 \\
\hline 2 & & & & 0.76 & $0.51-1.14$ & 0.18 \\
\hline 3 & & & & 1.04 & $0.67-1.61$ & 0.87 \\
\hline$\geq 4$ & & & & Ref & - & - \\
\hline \multicolumn{7}{|l|}{ OS Drug Used } \\
\hline None & & & & 0.52 & $0.18-1.50$ & 0.22 \\
\hline Clomid or Letrozole & & & & 0.51 & $0.31-0.85$ & 0.010 \\
\hline Gonadotropin & & & & Ref & - & - \\
\hline
\end{tabular}

Model 1: adjusted for patient factors only

Model 2: adjusted for both patient and care-related factors

gestational sac and fetal heartbeat $[10,13,15]$ or delivery rate [8]. We present results for the latter two outcomes, recognizing that data about live births was available only for $83 \%$ of the clinical pregnancies.

Recommended minimum NMSI thresholds for IUI vary widely across the literature, with reports of 1 million [8], 2 million [7], 5 million [10], and 10 million [9], when calculated for female patients of all ages. It is important to elicit the impact of differing NMSI levels that may exist according to female age, which is known to be an independent predictor of success following IUI [11].

When not stratified by age category, our results showed that the odds of $\mathrm{CP}$ per round were significantly decreased with increasing female age, average NMSI $<1.0\left(\times 10^{6}\right)$, and duration of fertility $\geq 36$ months. Odds of $\mathrm{CP}$ per cycle were likewise significantly reduced when the NMSI was < 1.0, and with increasing female age when adjusted for both patient- and care-related factors.

Only a few studies have considered NMSI according to female age; Demir et al. found that pregnancy rates were only significantly different in the group of women $<25$ years when NMSI was $>10 \times 10^{6}$, compared to age groups 25-30 and $>30$, and NMSI categories of $<5$ and 5-10 [13]. Similarly, Badawy, et al. found that pregnancy rates were significantly different also in the group of women $<25$ years, but only when NMSI was $>5 \times 10^{6}$ (compared to any NMSI category $<5$ and women 25-30, $30-35$, and 35-40 years) [12]. Both of these results argue against the NMSI as a useful predictor of success in patients above the age of 25 [12, 13].

In our study, pregnancy rates were only significantly different in the group $<35$ years when NMSI was $<5.0$, 
Table 6 Odds of Clinical Pregnancy per cycle according to NMSI and Age Category

\begin{tabular}{|c|c|c|c|c|c|c|}
\hline \multicolumn{2}{|l|}{ Unadjusted Models } & \multicolumn{3}{|c|}{$\begin{array}{l}\text { Model } 1 \\
\text { Age }<35 \\
\text { ( } N=1208 \text { cycles from } 455 \text { couples) }\end{array}$} & \multicolumn{2}{|c|}{$\begin{array}{l}\text { Model } 2 \\
\geq 35 \\
(N=852 \text { cycles from } 315 \text { couples })\end{array}$} \\
\hline NMSI Category & $\mathrm{N}$ & OR $(95 \% \mathrm{Cl})$ & $P$-Value & $\mathrm{N}$ & OR $(95 \% \mathrm{Cl})$ & P-Value \\
\hline $0-4$ & 227 & $0.48(0.30-0.77)$ & 0.002 & 136 & $\begin{array}{l}0.84 \\
(0.46-1.54)\end{array}$ & 0.57 \\
\hline $5-9$ & 142 & $0.65(0.38-1.11)$ & 0.12 & 103 & $\begin{array}{l}0.78 \\
(0.39-1.54)\end{array}$ & 0.47 \\
\hline$\geq 10$ & 839 & Ref & - & 613 & Ref & - \\
\hline \multicolumn{2}{|l|}{ Adjusted Models } & \multicolumn{3}{|c|}{$\begin{array}{l}<35 \\
(N=1053 \text { cycles from } 389 \text { couples })\end{array}$} & \multicolumn{2}{|c|}{$\begin{array}{l}\geq 35 \\
(N=742 \text { cycles from } 269 \text { couples })\end{array}$} \\
\hline \multicolumn{2}{|l|}{ NMSI Category } & OR $(95 \% \mathrm{Cl})$ & \multicolumn{2}{|l|}{ P-Value } & OR $(95 \% \mathrm{Cl})$ & P-Value \\
\hline $0-4$ & 204 & $0.49(0.29-0.83)$ & 0.007 & 119 & $1.55(0.72-3.31)$ & 0.26 \\
\hline $5-9$ & 127 & $0.66(0.37-1.18)$ & 0.17 & 94 & $1.04(0.48-2.27)$ & 0.92 \\
\hline$\geq 10$ & 722 & Ref & - & 529 & Ref & - \\
\hline \multicolumn{7}{|c|}{ Duration of Infertility (Months) } \\
\hline$<12$ & 76 & Ref & - & 97 & Ref & - \\
\hline $12-23$ & 501 & $0.82(0.42-1.62)$ & 0.57 & 354 & $0.91(0.44-1.91)$ & 0.81 \\
\hline $24-35$ & 268 & $0.98(0.48-2.01)$ & 0.96 & 138 & $0.91(0.40-2.09)$ & 0.82 \\
\hline$\geq 36$ & 208 & $0.51(0.23-1.12)$ & 0.09 & 153 & $0.70(0.31,1.59)$ & 0.39 \\
\hline \multicolumn{7}{|l|}{ Cause of Infertility } \\
\hline Unexplained & 427 & $0.93(0.62-1.38)$ & 0.70 & 336 & $0.97(0.60-1.65)$ & 0.91 \\
\hline Male \& Female Factor & 51 & $0.53(0.20-1.41)$ & 0.21 & 65 & $0.45(0.09-2.35)$ & 0.35 \\
\hline Male Factor & 218 & $0.93(0.58-1.50)$ & 0.77 & 138 & $0.21(0.08-0.53)$ & 0.001 \\
\hline Female Factor & 357 & Ref & - & 203 & Ref & - \\
\hline
\end{tabular}

suggesting that NMSI is not a good predictor of success in patients over 35 years. Although this study only considered two categories of ages $(<35$ and $\geq 35)$, our finding is consistent with those of the aforementioned studies, in that the NMSI is not a useful predictor of success in older patients $[12,13]$.

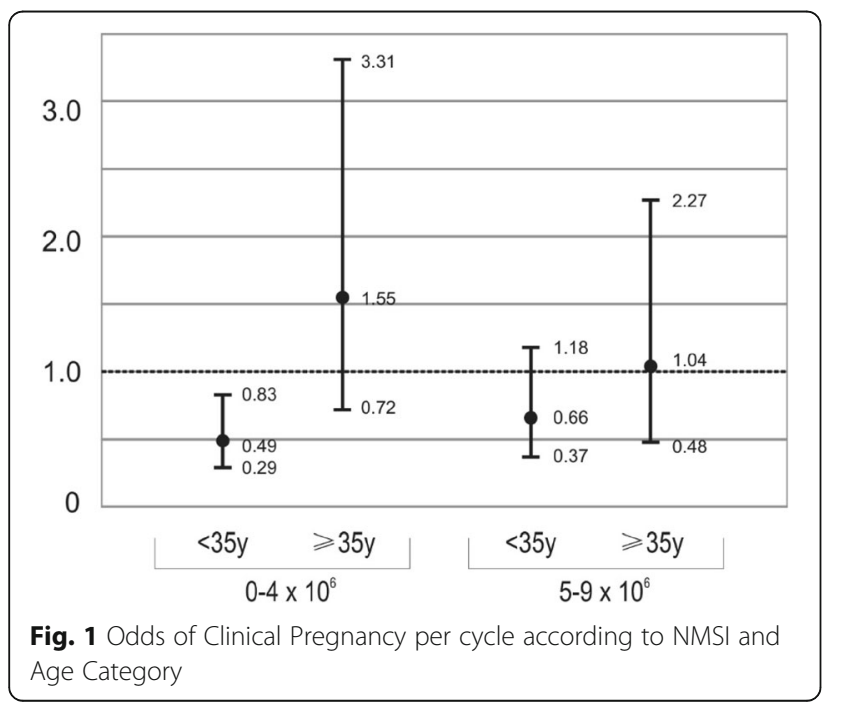

When compared in groups $<35$ and $\geq 35$ years, odds of $\mathrm{CP}$ per cycle were significantly reduced only in patients $<35$ years and NMSI 0-4, when either adjusted or unadjusted for other patient-related factors. This unexpected result of lower pregnancy rates in patients $<35$ vs. those $\geq 35$ within the same NMSI category may be due to selection bias. It is possible that patients who presented at increased maternal age with perceived unfavourable characteristics for IUI were referred to other ARTs earlier or did not proceed with IUI at all. Likewise, those patients presenting with low NMSI initially may have been referred earlier, resulting in the relatively small cohort of patients with NMSI $<1 \times 10^{6}$ in this study.

The NMSI may have unique value as a prognostic tool in that it reflects both sperm concentration and motility, as well as the effects of sperm processing [6]. The limitation is that it cannot be used for counselling during the initial infertility workup, but only during/after the IUI procedure. As such, the utility of the NMSI as predictor of pregnancy rates has been questioned. The baseline TMSC and sperm morphology will guide the pregnancy rates counselling during the initial infertility workup. If with the baseline sperm parameters a couple is eligible for IUI, the 
Table 7 Live birth outcomes

\begin{tabular}{|c|c|}
\hline Outcomes for all Positive Fetal Heart Rate, n (\%) & $N=312$ \\
\hline Live Births & $220(84.0)$ \\
\hline Miscarriages $^{a}$ & $36(13.7)$ \\
\hline Not Yet Delivered & $6(2.3)$ \\
\hline Unknown, n & 50 \\
\hline $\begin{array}{l}\text { Pregnancy Outcomes for all deliveries } \\
\text { at Kingston General Hospital }\end{array}$ & $N=196$ \\
\hline \multicolumn{2}{|l|}{ GA at delivery (weeks), n (\%) } \\
\hline Extremely preterm $(<28)$ & $5(2.6)$ \\
\hline Very preterm (28-31) & $3(1.5)$ \\
\hline Moderate preterm (32-33) & $3(1.5)$ \\
\hline Late preterm (34-37) & $30(15.3)$ \\
\hline Term $(\geq 37)$ & $155(79.1)$ \\
\hline \multicolumn{2}{|l|}{ Type of Delivery, n (\%) } \\
\hline Spontaneous Vaginal & $97(49.5)$ \\
\hline Assisted Vaginal & $20(10.2)$ \\
\hline Cesarean Section & $79(40.3)$ \\
\hline \multicolumn{2}{|l|}{ Number of Babies, n (\%) } \\
\hline Singleton & $162(82.7)$ \\
\hline Twins & $30(15.3)$ \\
\hline Triplets & $4(2.0)$ \\
\hline \multicolumn{2}{|l|}{ Pregnancy Complications, n (\%) } \\
\hline Gestational Diabetes & $17(8.7)$ \\
\hline Hypertensive Disorder & $21(10.7)$ \\
\hline Pre-existing Hypertension & $3(1.5)$ \\
\hline $\begin{array}{l}\text { Outcomes for all babies delivered at } \\
\text { Kingston General Hospital } \\
\text { ( } \geq 37 \text { weeks gestation) }\end{array}$ & $N=172$ \\
\hline Birthweight (grams), mean (SD) & $\begin{array}{l}3404 \\
(542)\end{array}$ \\
\hline$<2500, \mathrm{n}(\%)$ & $10(5.9)$ \\
\hline 2500-2999, n (\%) & 27 (15.9) \\
\hline 3000-3999, n (\%) & $110(64.7)$ \\
\hline$\geq 4000, n(\%)$ & $23(13.5)$ \\
\hline Unknown, n & 2 \\
\hline \multicolumn{2}{|l|}{ APGAR Scores, n (\%) } \\
\hline Normal $(\geq 7)$ at $1 \mathrm{~min}$ & $151(87.8)$ \\
\hline Normal $(\geq 7)$ at $5 \mathrm{~min}$ & $167(97.1)$ \\
\hline Unknown, n & 3 \\
\hline $\begin{array}{l}\text { Outcomes for all babies delivered at Kingston General } \\
\text { Hospital }\end{array}$ & $N=236$ \\
\hline \multicolumn{2}{|l|}{ APGAR Scores, n (\%) } \\
\hline Normal $(\geq 7)$ at $1 \mathrm{~min}$ & $184(78.0)$ \\
\hline Normal $(\geq 7)$ at $5 \mathrm{~min}$ & $213(90.3)$ \\
\hline Unknown, n & 13 \\
\hline
\end{tabular}

${ }^{\mathrm{a}}$ includes elective terminations
NMSI will help to determine during the course of IUI if a couple is not suitable anymore for this type of treatment and should move to different ART options.

\section{Conclusions}

These results suggest that NMSI can be used as a predictor of success in IUI in patients who are $<35$ years of age; these patients may be advised to pursue other ARTs when NMSI is $<5.0 \times 10^{6}$. In patients $\geq 35$ years, NMSI does not appear to be a useful predictor of success; more research is needed to determine other factors that are predictive of success with IUI in this age group.

\section{Abbreviations}

ART: Assisted reproductive technologies; CP: Clinical pregnancy; ICSI: Intracytoplasmic sperm injection; IUI: Intrauterine Insemination; IVF: In vitro fertilization; NMSI: Motile spermatozoa inseminated; OS: Ovarian stimulation

\section{Acknowledgements}

Not applicable.

\section{Authors' contributions}

PGG: conceptualization and drafting; JP: conceptualization, statistical analysis, and revision; DW: Data acquisition and revision; RLR: revision; MPV: Funding acquisition, conceptualization, and revision. All authors read and approved the final manuscript.

\section{Funding}

This study was supported by the Canadian Institutes of Health Research (CIHR). Grant number MFM - 146444. Palma G. Gubert was funded by the Department of Obstetrics and Gynecology, Queen's University.

\section{Availability of data and materials}

The datasets analysed during the current study are available from the corresponding author on reasonable request.

\section{Ethics approval and consent to participate}

This study was approved by the Queen's University Health Sciences \& Affiliated Teaching Hospitals Research Ethics Board (HSREB 6023673).

\section{Consent for publication}

Not applicable.

\section{Competing interests}

The authors declare that they have no competing interests.

Received: 13 May 2019 Accepted: 21 August 2019

Published online: 02 September 2019

\section{References}

1. Cohlen B, Bijkerk A, Van der Poel S, Ombelet W. IUI: review and systematic assessment of the evidence that supports global recommendations. Hum Reprod Update. 2018;24(3):300-19.

2. Bensdorp AJ, Tjon-Kon-Fat Rl, Bossuyt PM, Koks CA, Oosterhuis GJ, Hoek A, et al. Prevention of multiple pregnancies in couples with unexplained or mild male subfertility: randomised controlled trial of in vitro fertilisation with single embryo transfer or in vitro fertilisation in modified natural cycle compared with intrauterine insemination with controlled ovarian hyperstimulation. BMJ. 2015;350:g7771.

3. Tjon-Kon-Fat Rl, Bensdorp AJ, Bossuyt PM, Koks C, Oosterhuis GJ, Hoek A, et al. Is IVF-served two different ways-more cost-effective than IUI with controlled ovarian hyperstimulation? Hum Reprod. 2015:30(10):2331-9.

4. Jeon YE, Jung JA, Seo SK, Cho S, Choi YS, Lee BS. Predictive factors for pregnancy during the first four intrauterine insemination cycles using gonadotropin. Gynecol Endocrinol. 2013;29(9):834-8. 
5. Ombelet W, Dhont N, Thijssen A, Bosmans E, Kruger T. Semen quality and prediction of IUI success in male subfertility: a systematic review. Reprod BioMed Online. 2014;28(3):300-9.

6. van Weert JM, Repping S, Van Voorhis BJ, van der Veen F, Bossuyt PM, Mol BW. Performance of the postwash total motile sperm count as a predictor of pregnancy at the time of intrauterine insemination: a meta-analysis. Fertil Steril. 2004;82(3):612-20.

7. Cao S, Zhao C, Zhang J, Wu X, Zhou L, Guo X, et al. A minimum number of motile spermatozoa are required for successful fertilisation through artificial intrauterine insemination with husband's spermatozoa. Andrologia. 2014 46:529-34.

8. Dinelli L, Courbière B, Archard V, Jouve E, Deveze C, Gnisci A, et al. Prognosis factors of pregnancy after intrauterine insemination with the husband's sperm: conclusions of an analysis of 2,019 cycles. Fertil Steril. 2014:101(4):994-1000.

9. Miller DC, Hollenbeck GD, Randolph JF, Christman GM, Smith YR, Lebovic DI, et al. Processed total motile sperm count correlates with pregnancy outcome after intrauterine insemination. Urology. 2002;60(3):497-501.

10. Wainer $R$, Albert $M$, Dorion $A$, Bailly $M$, Bergère $M$, Lombroso $R$, et al. Influence of the number of motile spermatozoa inseminated and of their morphology on the success of intrauterine insemination. Hum Reprod. 2004:19(9):2060-5.

11. Sicchieri F, Silva AB, ACJDSRE S, PAAS N, Ferriani RA, dos Reis RM. Prognostic factors in intrauterine insemination cycles. JBRA Assist Reprod. 2017;22:2-7.

12. Badawy A, Elnashar A, Eltotongy M. Effect of sperm morphology and number on success of intrauterine insemination. Fertil Steril. 2009;91(3): 777-81.

13. Demir B, Dilbaz B, Cinar O, Karadag B, Tasci Y, Kocak M, et al. Factors affecting pregnancy outcome of intrauterine insemination cycles in couples with favourable female characteristics. J Obstet Gynaecol. 2011;31(5):420-3.

14. Lemmens L, Kos $S$, Beijer C, Brinkman JW, van der Horst FAL, van den Hoven $L$, et al. Predictive value of sperm morphology and progressively motile sperm count for pregnancy outcomes in intrauterine insemination. Fertil Steril. 2016:105(6):1462-8

15. Hamilton JA, Cissen M, Brandes M, Smeenk JM, de Bruin JP, Kremer JA, et al. Total motile sperm count: a better indicator for the severity of male factor infertility than the WHO sperm classification system. Hum Reprod. 2015; 30(5):1110-21.

\section{Publisher's Note}

Springer Nature remains neutral with regard to jurisdictional claims in published maps and institutional affiliations.

Ready to submit your research? Choose BMC and benefit from:

- fast, convenient online submission

- thorough peer review by experienced researchers in your field

- rapid publication on acceptance

- support for research data, including large and complex data types

- gold Open Access which fosters wider collaboration and increased citations

- maximum visibility for your research: over $100 \mathrm{M}$ website views per year

At $\mathrm{BMC}$, research is always in progress.

Learn more biomedcentral.com/submissions 